\title{
Günümüzde total diz artroplastisinde uygulanan çimentolama yöntemleri
}

\section{Current cementing methods in total knee arthroplasty}

\author{
Çağrı Örs, Yaman Sarpel \\ Özel Ortopedia Hastanesi, Diz ve Spor Cerrahisi Bölümü, Adana
}

Total diz protezi ameliyatı son dönem diz artriti (gonartroz) olan hastaların tedavisinde uzun yıllardır başarı ile uygulanan bir yöntemdir. Cerrahinin başarısını, komponentlerin tespit gücünü ve protez sağkalımını arttırmak için birçok çimentolama yöntemi kullanılmıştır. Yıllar içerisinde, çimentolama yöntemi ve tekniği teknolojik gelişmeler ve değişiklikler göstermiştir. Ancak, total diz protezi cerrahisinde optimum çimentolama tekniği halen tartışmalıdır. Çimentolama tekniği, uygulanan çimento miktarı, çimento penetrasyon derinliği ve uygulama öncesi yapılan kemik yüzey hazırlıkları, cerrahın tercihine bağlıdır ve dolayısıyla çok geniş bir perspektifte çeşitlilik gösterir. Klinik ve deneysel çalışmalar sonucunda birçok teknik önerilmiş ve çelişkili sonuçlar ortaya çıkmıştır. Genel görüş olarak: kemik yüzey hazırlığının titiz yapılması ve yeterli çimento penetrasyonu, komponent tespiti için önemli parametrelerdir. Erken implant tespitindeki yetersizlikler, primer total diz protezi başarısızlığının en önemli ve en sık nedeni olan aseptik gevşemeye yol açmaktadır. Bu derleme makalede, güncel çimento uygulamaları ve uygulama tekniklerinin klinik ve deneysel sonuçlarını inceleyerek, güncel çimentolama yöntemlerini değerlendirmeyi amaçladık. Total diz protezi cerrahisinde tibial ve femoral komponent tespiti için kemik yüzey hazırlığını, tespit arttırıcı yöntemleri, çimento uygulamada kolaylık sağlayan tekniklerin sonuçlarını, güncel literatür eşliğinde değerlendirdik.

Anahtar sözcükler: total diz protezi; çimentolama; pulsatil lavaj; çimento penetrasyonu; protez tespit
Total knee arthroplasty surgery has been successfully applied for many years in the end-stage treatment of patients with last stage knee arthritis (gonarthrosis). A number of cementing methods have been used to increase prosthesis survival, success of the surgery, and for the strong fixation of components. Over the years, the methods and techniques of cementing have shown technological improvements and changes. However, optimum technique of cementing is still controversial among total knee arthroplasty surgeons. Cementation technique, amount of cement applied, depth of cement penetration, and bone surface preparations made before application depend on the preferences of the surgeon, and therefore, show a wide range of variation. As a result of many clinical and experimental studies, many techniques have been proposed and conflicting outcomes observed. As a general view: careful preparation of the bone surface and adequate cement penetration are important parameters for component fixation. Inefficiencies in the early implant fixation lead to aseptic loosening, which is the most important and frequent cause of primary total knee arthroplasty failure. In this review article, we aimed to evaluate the current cementing methods applied by examining the clinical and experimental results of current cementing applications and techniques. We evaluated the results of bone surface preparation, fixation enhancing methods, cement application and ease of application for tibial and femoral component fixation in total knee arthroplasty, in the context of current literature.

Key words: total knee prosthesis; cementation; pulsatile lavage; cement penetration; prosthesis fixation
T otal diz protezi (TDP) ameliyatı, ileri derecede diz artriti olan ve ameliyatsız tedavilerden yarar görmemiş hastalarda, ağrıyı azaltan ve diz fonksiyonlarını iyileştiren etkili bir cerrahidir. Diz protezi komponent tespitinde polimetilmetakrilat (PMMA) uzun yıllardır başarılı bir şekilde uygulanmış ve halen uygulanmaya devam etmektedir. Uzun dönem takiplerde, mekanik yetmezliklere (osteoliz) bağlı revizyonlar da değerlendirildiğinde, \%95'in üzerinde TDP sağkalımları elde edilmiştir. ${ }^{[1,2]}$

Çimentolu TDP uygulamalarının yanı sıra çimentosuz TDP uygulamaları ve bunun da ötesinde hibrid TDP uygulamaları mevcuttur. ${ }^{[3]}$ Çimentosuz TDP tespitleri daha az güvenilir bulunmuş ve pratik uygulamada

- İletişim adresi: Op. Dr. Çağrı Örs, Özel Ortopedia Hastanesi, Döşeme Mahallesi, Cumhuriyet Cad., No:64, Sey-han, Adana Tel: 0555 - 5702024 e-posta: cagriors@gmail.com

- Geliş tarihi: 24 Ocak $2019 \quad$ Kabul tarihi: 24 Ocak 2019 


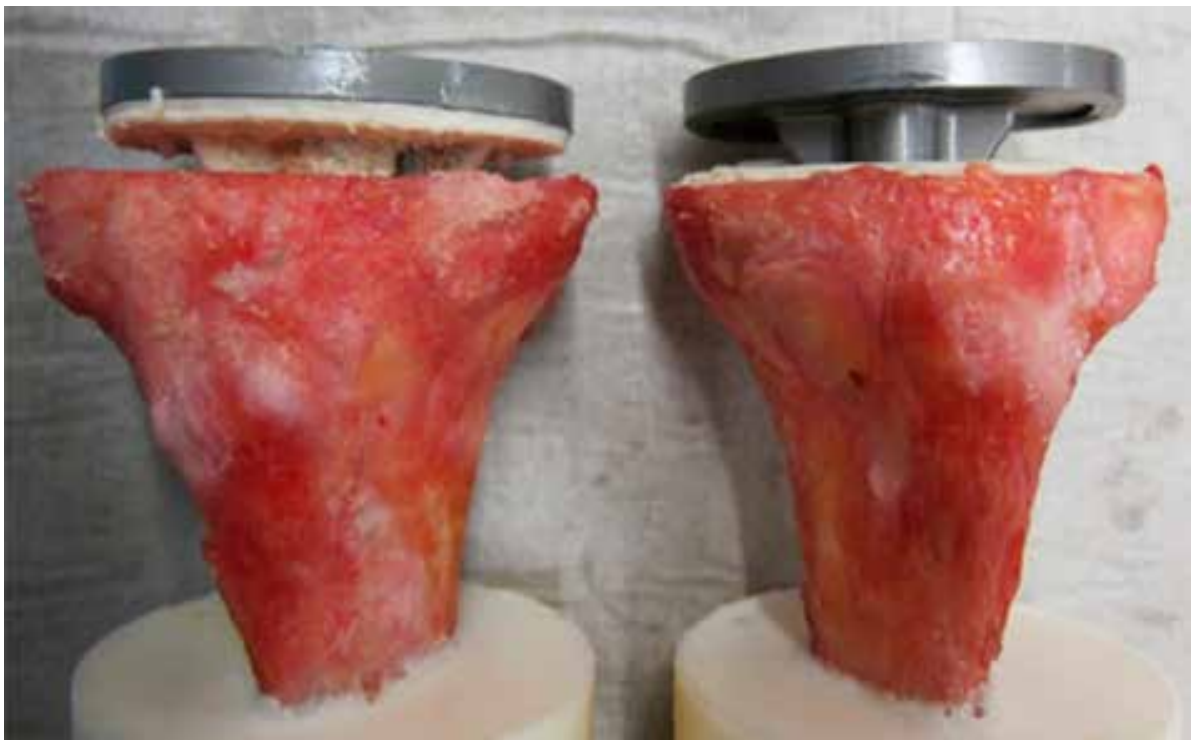

Şekil 1. Karakteristik başarısızlık paterni; şırınga lavaj uygulaması (a), pulsatil lavaj uygulaması (b).[14]

daha az yer bulmuştur. Bunun yanı sıra daha az oran$\mathrm{da}$, çimentolu ve çimentosuz TDP tespitlerinde protez tasarımına bağlı başarısızlıklar dışlandığında, her iki yöntemle de benzer başarılı sağkalım sonuçları elde edilen çalışmalar da mevcuttur. ${ }^{[4]}$ Ritter ve Meneghini, 20 yıllık takipte 73 çimentosuz TDP uygulamasında, sadece iki hastada aseptik gevşemeye bağlı tibial komponent başarısızlığı bildirmişlerdir. ${ }^{[5]}$

Çimentolu TDP uygulaması, halen ortopedik cerrahların en sık uyguladığı artroplasti cerrahisidir. Bu sık uygulanan cerrahi işlem, yıllar içerisinde gerek implant teknolojisinde, gerek çimento teknolojisinde gerekse de uygulanan cerrahi tekniklerde birçok gelişme ve değişiklikler göstermiştir.

Çimento uygulaması, çimento miktarı, çimento uygulaması öncesi hazırlık, penetrasyon miktarı ve çimentolama teknikleri, cerrahın tercihine bağlı olarak geniş bir perspektifte çeşitlilik içermektedir. ${ }^{[6]}$

\section{KEMIK YÜZEY HAZIRLIĞı}

TDP sonrası komponentlerin aseptik gevşemesi, cerrahi başarısızlık ve revizyon cerrahisinin önemli nedenlerindendir. TDP sonrası en sık gevşeme tibial tarafta görülür. ${ }^{[7]}$ Bu komplikasyonlar ile baş etmek için, TDP cerrahisinde tibial komponent tespitinde sıklıkla çimento kullanılır. ${ }^{[1-3]}$ Tibial komponentte çimento, tespit gücünü arttıracağı gerekçesiyle kullanılmaktadır. Tespitin gücü, kemik kalitesiyle birlikte, çimento penetrasyon derinliğiyle de ilişkilidir. Birçok çalışmada yazarlar, 3-4 mm'lik çimento penetrasyonunu kemikçimento ara yüzü direnci için yeterli görmüştür. ${ }^{[8-10]}$ Bunun yanı sıra, tibial komponentte çimento tespit gücünü yükseltmek için 1,1-5,6 mm arasında uygulanan çimento penetrasyonunun benzer biyomekanik stabilite gösterdiğini savunan, kadavra üzerinde yapılmış biyomekanik çalışmalar da mevcuttur. ${ }^{[11]}$ Yeterli çimento penetrasyonu için, kemik yüzey hazırlığı birincil önem arz etmektedir. Uygun proksimal tibial kesi sonrası kemik, maksimum stabilizasyon elde etmek için hazırlanmalıdır. Tibial plato üzerindeki bütün kemik debrisler, kan ve yumuşak dokular, kansellöz kemik üzerinden temizlenmelidir. Yaptıkları deneysel çalışmada Majkowski ve Bannister, stimüle edilmiş kanamanın, çimento penetrasyon derinliği üzerinde olumsuz etkilerini tespit etmişlerdir. ${ }^{[12]}$

Pulsatil lavaj, el ile veya şıınga yardımıyla yapılan irrigasyondan çok daha iyi bir debridman sağlar. Basınçı yıkama, basınçlı çimento tabancası veya geleneksel el ile çimento uygulaması ile kansellöz kemikte çimento penetrasyonunun arttırıldığı gösterilmiştir. ${ }^{[13]}$ Pulsatil lavaj kullanılarak yapılan yüzey irrigasyonunun, tibial komponent tespit kuvvetini arttırdığı gösterilmiştir (Şekil 1). Schlegel ve ark., pulsatil lavaj ile irrigasyonun TDP uygulamasında zorunlu ve önemli bir hazırlık aşaması olduğunu belirtmişlerdir. ${ }^{[14]}$

Debris ve kandan temizlenmiş, protez uygulanacak kemik yüzeyler, aspirasyon ve kuru gazlı bez yardımıyla kurutularak çimento uygulamasına hazır hale getirilmelidir. ${ }^{[13]}$ 
TDP'de femoral tarafta daha az sıklıkla tespit yetersizliği ve aseptik gevşemeyle karşılaşılsa da kemik yüzey hazırlığı özenli yapılmalıdır. Uygun femoral kesilerden sonra, basınçlı yıkama ile spongiyöz kemik yüzeyler debris ve kandan arındırılmalıdır. Femur distal ve anterior yüzey temizliği yeterli olsa da, posterior kesi yüzeyi irrigasyonu zorluk içerebilir ve yetersiz yapılabilir. Böyle bir durumda, özellikle posterior stabilize bir TDP implantı için, yetersiz çimento penetrasyonu, tespit yetersizliği ve sonuç olarak erken femoral komponent gevşemesi görülebilir. ${ }^{[15]}$

Cerrahi işleme başlarken veya çimento uygulama basamağından önce turnike işlemi uygulanması, komponent tespitini arttırmaya yardımcı olur. Çimento uygulaması öncesi turnike uygulaması, kanamayı minimalize ederek, komponent tespitini güçlendirir. ${ }^{[12]}$

Yapılan biyomekanik çalışmalarda, kansellöz kemikte çimento penetrasyonunun daha başarılı olduğu gösterilmiştir. ${ }^{[11]}$ Artritik eklemlerin bir komponenti olarak gelişen subkondral skleroz, yüzeyde çimento penetrasyonunu ve dolayısıyla komponent tespitini olumsuz etkiler. TDP cerrahisi sırasında çoğu zaman tibia mediyal platoda, daha az sıklıkla femoral yüzde sklerotik kemik ile karşılaşılabilir. Sklerotik kemiğe çoklu delikler açarak çimento penetrasyonu arttırılabilir. Yapılan karşılaştırmalı klinik çalışmada, $4,5 \mathrm{~mm}$ çaplı drill ile $5 \mathrm{~mm}$ 'lik aralıklar ve $4 \mathrm{~mm}$ 'lik derinlikte yapılan çoklu drilleme yönteminin, düşük çaplı yönteme oranla daha iyi çimento penetrasyonu sağladığı ve daha az radyolüsen hat oluşumu gösterdiği belirtilmiştir. ${ }^{16]}$

\section{ÇIMENTO UYGULAMASI}

Günümüzde, TDP cerrahisinde en ideal çimento uygulama yöntemleri halen tartışmalıdır. Özellikle tibial tarafta çimento uygulama yöntemleri üzerinde konsensus yoktur. ${ }^{[6]}$

Uygun kemik kesiler yapıldıktan ve sklerotik kemik yüzeyler uygun çimento penetrasyonu için hazırlandıktan sonra, basınçlı yıkama yöntemleri ile kemik hazırlığı yapılır. Yıkama sonrası kuru gazlı bez yardımıyla yüzey kurutulduktan sonra, manuel yöntemlerle veya vakumlu karıştırıcılar kullanılarak çimento hazırı̆̆g yapilır ve uygulamaya geçilir. ${ }^{[13]}$

Uzun yıllardır, PMMA çimento uygulaması artroplasti cerrahileri için kilit rol oynamaktadır. PMMA, yüzeye kolay uygulanarak, kemik ve implant arasında güçlü bağlantı kurar ve yükü kemiğe dağıtır. Birçok çalışmada, 3-4 mm'lik çimento penetrasyonunun sağlam komponent tespiti için yeterli olduğu savunulmuştur. ${ }^{[8-10]}$

Tibial yüzey hazırlığı sonrası, cerrahın tercihine ve tecrübesine bağlı olarak, farklı çimento uygulama yöntemleri kullanılabilir. Bunlardan bazıları; 1) sadece tibial komponent yüzeyinin altına çimento uygulaması, 2) tibial komponentin yüzeyine ve steme çimento uygulaması, 3) sadece tibial plato kemik yüzeyine çimento uygulaması ve 4) hem tibial komponent yüzeyine hem de kemik yüzeye, her ikisine birden çimento uygulamasıdır. Bu yöntemlerin kadavra üzerinde yapılan deneysel çalışmasında, radyolojik penetrasyon miktarları ve biyomekanik çekme testlerinde benzer sonuçlar elde edilmiştir. Bu çalışmada ve daha önceki çalışmalarda da özellikle, uygulama yönteminden ziyade basınçlı yıkama ile yapılan yüzey hazırlı̆̆ının önemi vurgulanmıştır. ${ }^{[14,17]}$

Uygun femur kesileri tamamlandıktan ve spongiyöz yüzey temizliği ve kurutulması yapıldıktan sonra femoral komponent tespitinde çimento uygulaması, uzun yıllardır başarı ile uygulanan ve başarılı uzun dönem sağkalım sonuçları olan bir yöntemdir. Yakın zamanda çimentosuz femoral komponent tespit uygulamaları, çimentolu uygulamalarla benzer sonuçlar gösterse de yaygın olan eğilim çimentolu tespitten yanadır. ${ }^{[18-20]}$

TDP tamamı çimentolu komponent uygulamalarında uzun dönem sağkalım süreleri ve başarılı klinik sonuçlar bildirilmiştir. Bunun yanı sıra, başarılı hibrid çimentosuz TDP uygulamaları bildirilmiş olup, en büyük endişe tibial komponent komplikasyonları üzerinde olmuştur. ${ }^{[21]}$

Hibrid çimentosuz TDP uygulamalarında, femoral komponent çimentosuz uygulamaya daha uygun gibi görülmektedir. Yapılan bir randomize kontrollü çalışmada, femoral komponent çimentolamanın radyolojik ve klinik bir avantajı olmadığı görülmüştür. ${ }^{[18]}$

Femoral komponent çimento uygulaması; 1) femoral kesi yüzeyine uygulama, 2) femoral komponent yüzeyine uygulama veya 3 ) her iki yüzeye birlikte uygulama şeklinde, basınçlı çimento tabancasıyla veya parmak ile uygulanabilir.

Femoral distal ve anterior kesi yüzeyiyle birlikte komponent posterioruna çimento uygulaması ile femoral yüzey ve birlikte bütün femoral komponent yüzeylerine çimentonun birlikte uygulandığı iki çimento uygulama yönteminin karşılaştırıldığı klinik çalışmada, 486 hasta minimum beş yıl süreyle takip edilmiştir. Klinik ve radyolojik takiplerde, basınçlı olarak her iki yüzeye çimento uygulamasında femoral komponentlerin erken gevşeme ve revizyon oranlarının daha düşük olduğu gösterilmiştir. ${ }^{[22]}$

Femoral çimentolamada, posterior kondiller yüzeylerde zayıf çimentolama tekniğine bağlı erken gevşeme ile karşılaşılabilir. Posterior femoral kondilin, gerek basınçlı yıkama ile yüzey hazırlı̆ının yapılmasındaki zorluklardan gerekse implantasyona paralel yüzeyde olmasından dolayı, çimentolama ile ilgili bazı sorunlarla ve buna bağlı komponent tespitinde başarısızlıklarla karşılaşılabilir. ${ }^{[15]}$ Posterior kondil çimentolaması için 


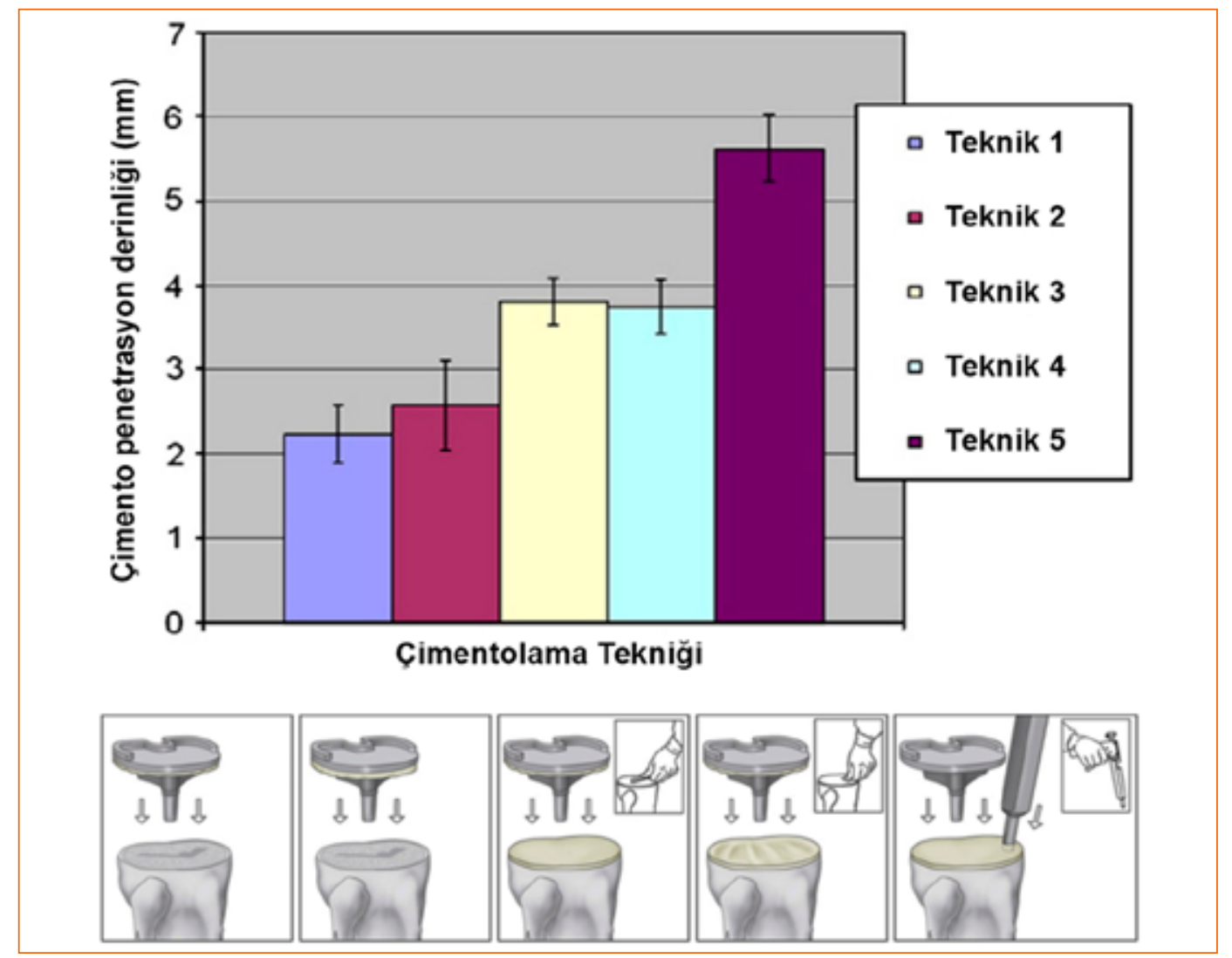

Şekil 2. Beş farklı çimentolama yöntemi ve ortalama çimento penetrasyon derinliği (Teknik 1, tibial komponentin alt yüzeyine $10 \mathrm{~g}$ çimento uygulaması; Teknik 2, tibial komponentin alt yüzeyine $20 \mathrm{~g}$ çimento uygulaması; Teknik 3, tibial komponentin alt yüzeyine ve tibianın kemik yüzeyine eşit miktarda spatulayla $20 \mathrm{~g}$ çimento uygulaması; Teknik 4, tibial komponentin alt yüzeyine ve tibianın kemik yüzeyine eşit miktarda parmak basıncıyla $20 \mathrm{~g}$ çimento uygulaması; Teknik 5, çimento tabancasıyla tibia kemik yüzeyine $20 \mathrm{~g}$ çimento uygulaması). ${ }^{[26]}$

basınçlı $65^{\circ}$ sabit açılı enjektör kullanılarak ve kullanılmadan çimento tabancasıyla çimento uygulama tekniğinin karşılaştırıldığı deneysel çalışmada; basınçlı enjeksiyon yapılan grupta, tüm yüzeylerde daha fazla çimento penetrasyonu gözlenmiştir. Fakat görsel ve radyolojik değerlendirmede, iki teknik arasında anlamIı fark tespit edilmemiştir. ${ }^{[15]}$

\section{ÇiMENTOLAMA TEKNIĞi}

Çimentolama tekniğiyle birlikte, çimento penetrasyonu TDP'de implant stabilitesi için çok önemli bir rol oynamaktadır. ${ }^{[23-25]}$ Çimento uygulaması, yıllar içerisinde değişiklikler ve ilerlemeler göstermiş birçok farklı teknikle yapılabilir. Çimento uygulaması; parmak ile manuel olarak, parmak basıncı uygulanarak, spatula yardımlı veya basınçlı çimento tabancası kullanılarak, düşük viskositeli olarak yapılabilmektedir. Bu yöntemlerin sonuçları tartışmalıdır ve üzerinde bir konsensus oluşmamıştır.
Vanlommel ve ark., osteoporotik kemik modelleri üzerinde yaptıkları çalışmada, beş farklı çimento uygulama yöntemini karşılaştırmışlardır. Sadece tibial komponent yüzeyine çimento uygulamasının yetersiz (2-3 mm), çimento tabancası ile ise çok fazla çimento penetrasyonu (5-6 mm) olduğunu; hem tibial komponent hem de tibial kemik yüzeyine parmak basıncı ile çimento uygulamasının optimal çimento penetrasyonu (3-4 mm) sağladığını göstermişlerdir (Şekil 2). ${ }^{[26]}$

TDP'de vakumlu karıştırıcı ve tabancalı basınçlı çimento uygulaması (Şekil 3) ile elle karıştırılıp manuel çimento uygulama yöntemlerinin karşılaştırıldığı geriye dönük çalışmada; tabancalı basınçlı çimento uygulaması yapılan grupta femur ön-arka planda 7. bölgede ve tibia yan planda 2 . bölgede daha iyi çimento penetrasyonu izlenmesine rağmen, benzer sonuçlar görüldügü belirtilmiştir. Bunun yanı sıra, tabancalı ve basınçlı çimento uygulanan grupta turnike süresi ve operasyon süresi anlamlı oranda daha uzun olmuştur. Vakumlu 


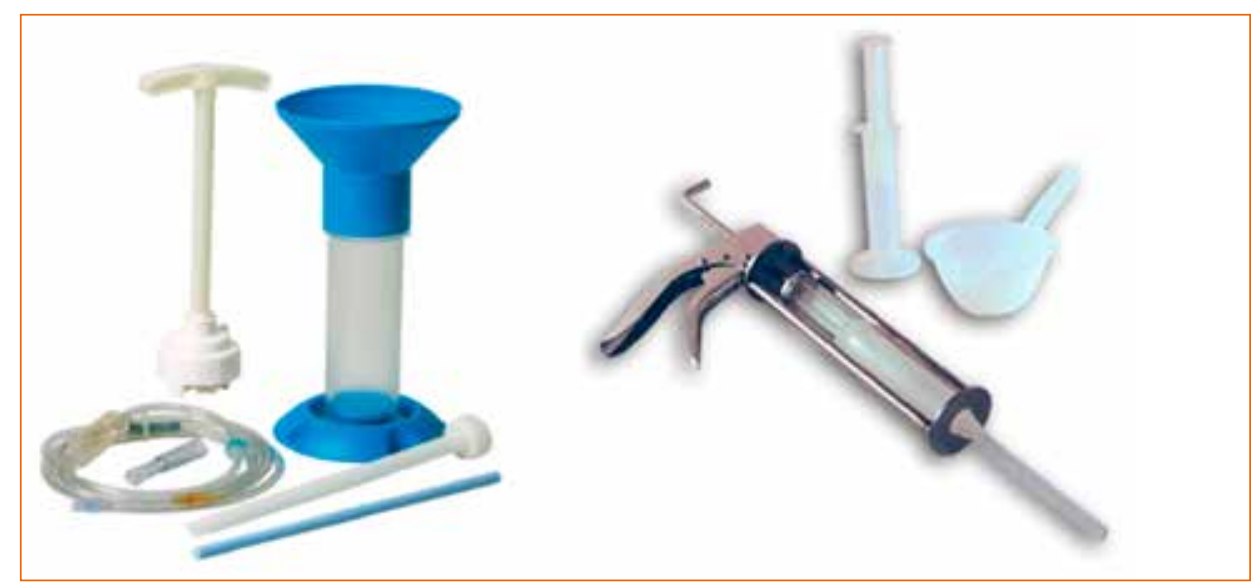

Şekil 3. Vakumlu çimento karıştırıcı ve basınçlı çimento tabancası.

karıştırma ve tabancalı basınçlı uygulama yönteminin, bariz bir avantajı olmasa da, uzun dönem takiplerinin yapılması gerektiği bildirilmiştir. ${ }^{[27]}$

Tibial ve femoral komponentler yerleştirildikten sonra deneme insert'i uygulanır ve artık çimentolar kemik yüzeylerden sıyrılarak temizlenir. Proksimal yönde, ekstremite uzun aksına uygun direkt kuwvet uygulanır ve çimentonun tam olarak sertleşmesi beklenir. ${ }^{15]}$

Çimento sertleştirme işlemi çoğu zaman tek basamaklı yapılır. ${ }^{[19]}$ Buna rağmen, erken çimento sertleşmesi veya cerrahi teknik gecikmelerin olduğu durumlarda, tibia ve femur için ayrı ayrı olarak, iki basamaklı uygulama yapılabilir.

\section{RADYOLOJiK DEĞERLENDIRME}

TDP sonrası çekilen direkt grafilerde tespit edilen, $2 \mathrm{~mm}$ 'nin altındaki ve ilerleyici olmayan radyolüsen hatlar, çoğu zaman klinik sonuçlarla ilişkili değildir ve revizyon kararı aldıracak bir neden de değildir. ${ }^{[20,23,28]}$ Tibial komponentte ilerleyici olmayan radyolüsen hatlar, çoğu zaman yetersiz çimento penetrasyonu olan sklerotik kemiklerden kaynaklanır ve bu da komponent tespitini etkilemez. ${ }^{[20]}$

Fakat, implant-kemik ara yüzüne eklem sıvısı sızması veya debris girmesine bağlı, protezde aseptik gevşeme meydana gelebilir. Femoral komponent gevşemesi gibi ikincil durumlarda da, agresif bir osteoliz gerçekleşip, hızlı aşınma sürecine ve ilerleyici radyolüsen hat gelişimine neden olan, ikinci tip radyolüsensi gelişebilir ki, bu durumda çoğu zaman revizyon ihtiyacı duyulur. ${ }^{[20]}$

TDP'de radyolüsensi ile çimentolama tekniği arasındaki ilişkiyi değerlendirmek için yapılan ileriye dönük çalışmada, üç farklı çimentolama tekniği karşılaştırılmıştır. Birinci grupta enjektör yardımlı irrigasyon ve elle çimento, ikinci grupta yüksek basınçlı ve volümlü irrigasyon ile elle çimento ve üçüncü grupta ise yüksek basınçlı ve volümlü irrigasyon ve düşük viskositeli basınçlı enjeksiyon ile çimento uygulanan 221 hasta (363 TDP) çalışmaya dahil edilmiştir. Bu çalışmada, basınçlı yıkama ile yapılan uygun yüzey hazırlığı ve basınçlı çimento uygulamasının radyolüsen hat oluşumunu azalttığı gösterilmiş, fakat radyolüsen hatlar direkt olarak başarısızlıkla ilişkilendirilememiştir. ${ }^{[29]}$ TDP'de çimento uygulamasında, kemik yüzeylerin basınçlı yıkanması ve kurutulması sonrası basınçlı çimento uygulanması, çimento penetrasyonunu arttırarak radyolüsens oluşumu azalttığı için şiddetle önerilmektedir. ${ }^{[29]}$

\section{CERRAHIN TERCIHI}

Biz TDP'de, kısmi turnike uygulaması ile sadece çimentolama öncesi turnike uygulaması yapıyoruz. Diz tam fleksiyonda cerrahiye başlıyoruz. Diz açılımı sonrası kemik kesileri tamamladıktan sonra deneme protezi uyguluyor ve uygun kontrollerden sonra, bacak elevasyonda esmark (Esmarch) bandajı uygulayıp turnikeyi şişiriyoruz.

Önce femoral yüzeylere, kemik debrisler ve kanı temizlemek için yüksek basınçlı yıkama tabancası ile irrigasyon ve debridman yapıyoruz. Özellikle posterior kesi yüzeyini; yeterli oranda irrigasyon uygulayıp uygulamadığımızı kontrol ediyoruz. Kuru gazlı bezler yardımıyla yüzeyi kurutuyoruz ve adrenalin emdirilmiş nemli gazlı bezlerle yüzeyi örtüp tibial yüzey hazırlığına başlıyoruz. Benzer şekilde, tibial yüzey hazırlığı yapıldıktan sonra, eğer varsa tibia mediyal platoda sklerotik yüzeylere 5'er $\mathrm{mm}$ aralıklarla, 4,5 mm'lik drill ile yaklaşık $4 \mathrm{~mm}$ derinlikte çoklu drilleme uyguluyoruz (Şekil 4). 


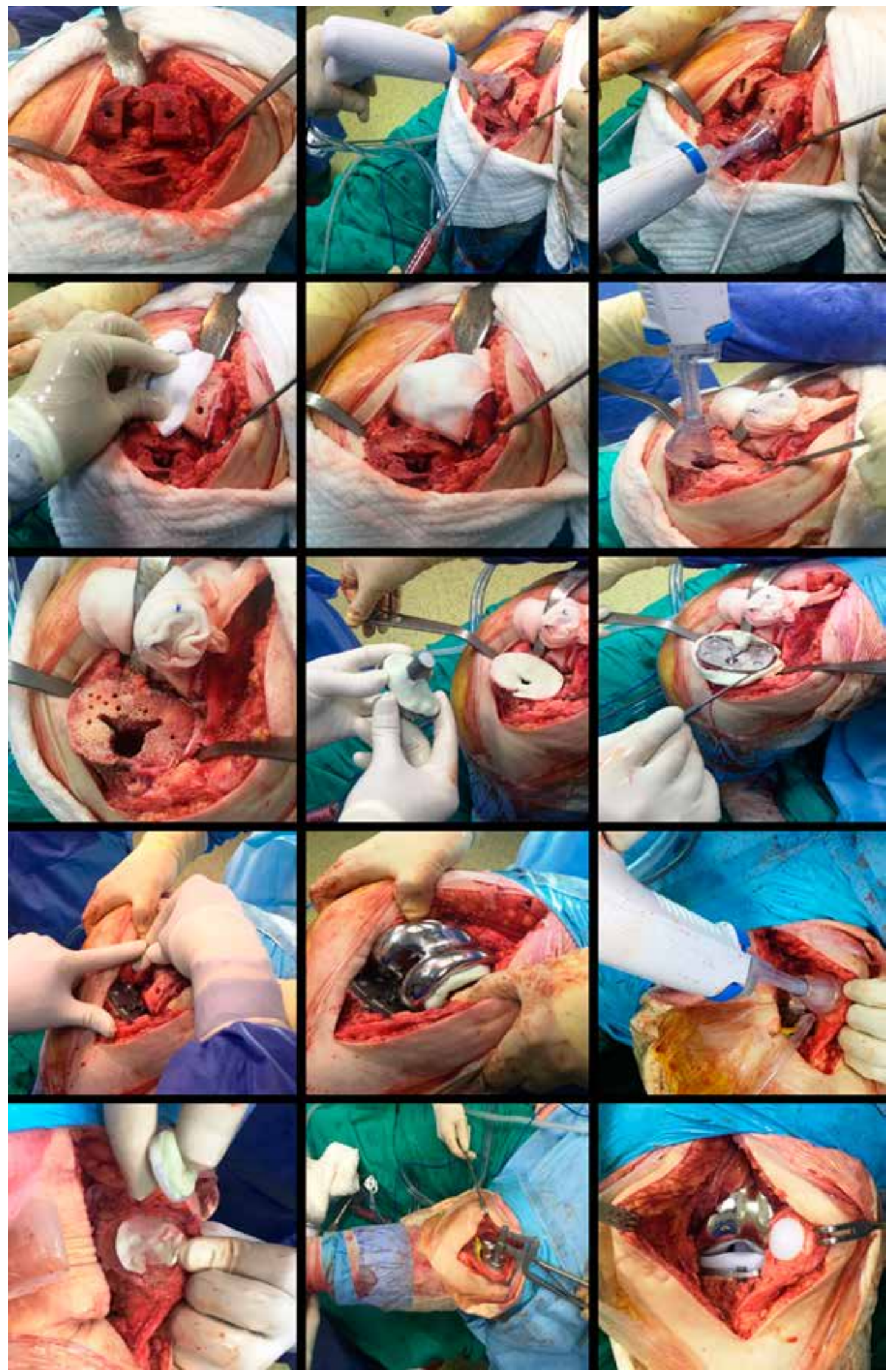

Şekil 4. Cerrahın çimentolama tekniği. 
Çimentoyu manuel olarak, hamur kıvamına gelinceye ve eldivene yapışmayıncaya kadar sürekli olarak usulüne uygun şekilde karıştırıyoruz. Tibial kemik yüzeye parmak yardımlı basınçlı çimento ve tibial komponent yüzeyine çimento ile komponenti uyguluyoruz. Çimento artıklarını, çimento sıyırıcısı yardımıyla temizliyoruz. Femoral yüzde femur distal ve anterior kemik yüzeye, femoral komponentin ise bütün yüzeylerine çimento uyguluyoruz. Femoral komponent posterioruna, komponent yüzeyini tamamen kaplayacak kadar çimento uyguluyoruz. Benzer şekilde, çimento temizliğini yaptıktan sonra deneme insert'i uyguluyor ve patellar komponente geçiyoruz. Patellar komponenti, hem kemik yüzeye parmak yardımlı basınçlı olarak hem de komponent yüzeyine çimento sürdükten sonra, patellar komponent sıkıştırıcısı ile koyuyoruz. Tekrar çimento artıklarının kontrolünü yaptıktan sonra, çimento sertleşinceye kadar tam ekstansiyonda proksimal yönde ekstremite uzun aksına uygun direkt kuvvet uyguluyoruz ve çimentonun tam olarak sertleşmesini bekliyoruz. Çimento sertleşmesi sonrası orijinal insert'i uyguluyor ve katlar anatomik olarak kapatıldıktan sonra cerrahiye son veriyoruz (Şekil 4).

TDP'de çimentolama tekniği halen, cerrahın tercihi ve tecrübesine göre geniş bir yelpazede farklııklar göstermektedir. Manuel olarak parmak ile basınç uygulayarak kemik yüzeye ve komponent yüzeyine uygun çimentonun, birçok cerrah için yeterli tespit sağladığı görüşü vardır. Yeni nesil vakumlu çimento karıştırıcıları ve düşük veya yüksek viskozitede basınçlı çimento tabancası kullanımlarının avantajlı olduğu, fakat daha fazla ve uzun dönem takipli çalışmalara gerek duyulduğu görüşü hakimdir. Çimentolama yöntemi ve tekniğinden bağımsız olarak, kemik yüzey hazırlığının basınçlı yıkama yöntemleriyle ayrıntılı olarak yapılması gerekir. Ayrıca, spongiyöz kemik yüzey hazırlığı da mutlak yapılması gereken bir basamaktır.

\section{KAYNAKLAR}

1. Lachiewicz PF, Soileau ES. Fifteen-Year Survival and Osteolysis Associated with a Modular Posterior Stabilized Knee Replacement. J Bone Joint Surg Am 2009;91(6):1419-23. Crossref

2. Colizza WA, Insall JN, Scuderi GR. The posterior stabilized total knee prosthesis: Assessment of polyethylene damage and osteolysis after a ten-year-minimum follow-up. J Bone Joint Surg Am 1995;77(11):1713-20. Crossref

3. Baker PN, Khaw FM, Kirk LM, Esler CN, Gregg PJ. A randomised controlled trial of cemented versus cementless press-fit condylar total knee replacement:15-year survival analysis. J Bone Joint Surg Br 2007;89-B(12):1608-14. Crossref

4. Wang $H$, Lou $H$, Zhang $H$, Jiang J, Liu K. Similar survival between uncemented and cemented fixation prostheses in total knee arthroplasty: a meta-analysis and systematic comparative analysis using registers. Knee Surg Sports Traumatol Arthrosc 2014;22(12):3191-7. Crossref
5. Ritter MA, Meneghini RM. Twenty-year survivorship of cementless anatomic graduated component total knee arthroplasty. J Arthroplasty 2010;25(4):507-13. Crossref

6. Cawley DT, Kelly N, McGarry JP, Shannon FJ. Cementing techniques for the tibial component in primary total knee replacement. J Bone Joint Surg Br 2013;95-B(3):295-300. Crossref

7. Windsor RE, Scuderi GR, Moran MC, Insall JN. Mechanisms of failure of the femoral and tibial components in total knee arthroplasty. Clin Orthop Relat Res 1989;(248):15-20. Crossref

8. Askew MJ, Steege JW, Lewis JL, Ranieri JR, Wixson RL. Effect of cement pressure and bone strength on polymethylmethacrylate fixation. J Orthop Res 1984;1(4):412-20. Crossref

9. Krause WR, Krug W, Miller J. Strength of the cement-bone interface. Clin Orthop Relat Res 1982;(163):290-9. Crossref

10. Walker PS, Soudry M, Ewald FC, McVickar H. Control of cement penetration in total knee arthroplasty. Clin Orthop Relat Res 1984;(185):155-64. Crossref

11. Nagel K, Bishop NE, Schlegel UJ, Püschel K, Morlock MM. The Influence of Cement Morphology Parameters on the Strength of the Cement-Bone Interface in Tibial Tray Fixation. J Arthroplasty 2017;32(2):563-9.e1. Crossref

12. Majkowski RS, Bannister GC, Miles AW. The effect of bleeding on the cementbone interface: an experimental study. Clin Orthop Relat Res 1994;(299):293-7. Crossref

13. Norton MR, Eyres KS. Irrigation and suction technique to ensure reliable cement penetration for total knee arthroplasty. J Arthroplasty 2000;15(4):468-74. Crossref

14. Schlegel UJ, Siewe J, Delank KS, Eysel P, Püschel K, Morlock $\mathrm{MM}$, de Uhlenbrock AG. Pulsed lavage improves fixation strength of cemented tibial components. Int Orthop 2011;35(8):1165-9. Crossref

15. Labutti RS, Bayers-Thering $M$, Krackow KA. Enhancing femoral cement fixation in total knee arthroplasty. J Arthroplasty 2003;18(8):979-83. Crossref

16. Ahn JH, Jeong $\mathrm{SH}$, Lee $\mathrm{SH}$. The effect of multiple drilling on a sclerotic proximal tibia during total knee arthroplasty. Int Orthop 2015;39(6):1077-83. Crossref

17. Schlegel UJ, Bishop NE, Püschel K, Morlock MM, Nagel K. Comparison of different cement application techniques for tibial component fixation in TKA. Int Orthop (SICOT) 2015;39(1):47-54. Crossref

18. Demey G, Servien E, Lustig S, Selmi TA, Neyret P. Cemented versus uncemented femoral components in total knee arthroplasty. Knee Surg Sports Traumatol Arthrosc 2011;19(7):1053-9. Crossref

19. Guha AR, Debnath UK, Graham NM. Radiolucent lines below the tibial component of a total knee replacement (TKR) a comparison between single- and two-stage cementation techniques. Int Orthop 2008;32(4):453-7. Crossref

20. Smith S, Naima VS, Freeman MA. The natural history of tibial radiolucent lines in a proximally cemented stemmed total knee arthroplasty. J Arthroplasty 1999;14(1):3-8. Crossref

21. Carlsson A, Björkman A, Besjakov J, Önsten I. Cemented tibial component fixation performs better than cementless fixation: a randomized radiostereometric study comparing porouscoated, hydroxyapatite-coated and cemented tibial components over 5 years. Acta Orthop 2005;76(3):362-9. Crossref

22. Han HS, Lee MC. Cementing technique affects the rate of femoral component loosening after high flexion total knee arthroplasty. Knee 2017;24(6):1435-41. Crossref 
23. Hofmann AA, Goldberg TD, Tanner AM, Cook TM. Surface cementation of stemmed tibial components in primary total knee arthroplasty: minimum 5-year follow-up. J Arthroplasty 2006;21(3):353-7. Crossref

24. Endres S, Wilke A. Is cementing technique the cause of early aseptic loosening of the tibial component in total knee arthroplasty?: a report of 22 failed tibial components. Orthop Rev (Pavia) 2011;3(1):1-5. Crossref

25. Janssen D, Mann KA, Verdonschot N. Micro-mechanical modeling of the cement-bone interface: the effect of friction, morphology and material properties on the micromechanical response. J Biomech 2008;41(15):3158-63. Crossref

26. Vanlommel J, Luyckx JP, Labey L, Innocenti B, De Corte R, Bellemans J. Cementing the tibial component in total knee arthroplasty: which technique is the best? J Arthroplasty 2011;26(3):492-6. Crossref
27. Kopec M, Milbrandt JC, Duellman T, Mangan D, Allan DG. Effect of hand packing versus cement gun pressurization on cement mantle in total knee arthroplasty. Can J Surg 2009;52(6):490-4.

28. Rossi R, Bruzzone M, Bonasia DE, Ferro A, Castoldi F. No early tibial tray loosening after surface cementing technique in mobile-bearing TKA. Knee Surg Sports Traumatol Arthrosc 2010;18(10):1360-5. Crossref

29. Ritter MA, Herbst SA, Keating EM, Faris PM. Radiolucency at the bone-cement interface in total knee replacement: the effects of bone-surface preparation and cement technique. J Bone Joint Surg Am 1994;76-A(1):60-5. Crossref 